\title{
Urine neopterin as a parameter of disease activity in patients with systemic lupus erythematosus: comparisons with serum sIL-2R and antibodies to dsDNA, erythrocyte sedimentation rate, and plasma C3, C4, and C3 degradation products
}

\author{
K L Lim, A C Jones, N S Brown, R J Powell
}

\begin{abstract}
Objectives-To investigate urine neopterin as a parameter of disease activity in an unselected group of patients with systemic lupus erythematosus (SLE) and to study the relation between urine neopterin and certain patterns of organ disease and differing drug regimens in the treatment of SLE.

Methods-Neopterin was determined by high performance liquid chromatography in 115 early morning urine samples from 68 patients with SLE. Serum soluble interleukin 2 receptor (sIL-2R) and antibodies to double stranded DNA (dsDNA) were determined by enzyme linked immunosorbent assay (ELISA), and the erythrocyte sedimentation rate (ESR), plasma C3, C4, and C3 degradation products (C3dg) were measured in corresponding blood samples. Disease activity was scored using the British Isles Lupus Assessment Group (BILAG) index.
\end{abstract}

Results-Urine neopterin was significantly increased in patients with active and inactive SLE compared with the control group and was significantly higher in patients with active than in those with inactive SLE. Urine neopterin did not distinguish between subsets of patients with SLE with particular patterns of organ disease, as defined by the BILAG index, nor was its level primarily influenced by differing drug regimens. Levels of serum sIL-2R, antibodies to dsDNA, the ESR, and plasma $\mathrm{C} 3, \mathrm{C} 4$, and $\mathrm{C} 3 \mathrm{dg}$ were also significantly different between the patients with active and inactive SLE. Unlike urine neopterin there was considerable overlap in the values of these parameters between the two activity groups. Highly significant correlations found between urine neopterin and serum sIL-2R, ESR, and plasma C3, C4, and C3dg suggest the close association of neopterin with clinical activity in SLE. Multivariate logistic regression analysis showed that urine neopterin $>300 \mu \mathrm{mol}$ mol creatinine was a highly significant predictor of disease activity with an odds ratio of $3 \cdot 51$.
Conclusions-Determination of urine neopterin, a non-invasive, relatively simple and inexpensive measurement, appears to be the best parameter for assessing and monitoring disease activity and treatment in patients with SLE.

(Ann Rheum Dis 1993; 52: 429-435)

Numerous and varied abnormalities of the immune system have been reported in patients with systemic lupus erythematosus (SLE). ${ }^{1}$ In particular, increases in circulating $T$ lymphocytes bearing the activation markers HLA-DR and HLA-DP antigens, ${ }^{2}$ the early activation antigen $\mathrm{TLi}-\mathrm{SA}^{4}$ and membrane bound interleukin 2 receptors (IL-2R) ${ }^{5}$ have been documented, supporting the concept of $T$ lymphocyte upregulation. Particular attention has been focused on neopterin as an indicator of activation of the cellular immune system. ${ }^{6}$ Neopterin is a pyrazino-pyrimidine derivative formed from guanosine triphosphate within the biosynthetic pathway of biopterin, ${ }^{7}$ but unlike biopterin, which is an important cofactor in a number of enzymatic reactions, the physiological role of neopterin remains obscure. In vitro experiments have shown that neopterin is specifically produced by human macrophages when stimulated by interferon $\gamma$ released from activated $\mathrm{T}$ lymphocytes. ${ }^{89}$ Evidence exists that endothelial cells can be an important source of neopterin in vitro ${ }^{10}$ but as yet endothelial cell production of neopterin in vivo has not been shown. Nevertheless, increased neopterin has been shown to be an early, specific and sensitive marker of activation of the cellular immune system in several clinical settings including allograft rejection, acute viral intracellular bacterial and protozoan infections, autoimmune and inflammatory diseases, and certain malignant diseases. ${ }^{11}$

The erythrocyte sedimentation rate (ESR), plasma/serum complement levels, and antibodies to double stranded DNA (dsDNA) are accepted as measures of disease activity in SLE. Some patients, however, may have abnormalities in these tests for considerable periods yet show few clinical symptoms or functional deterioration of a major organ, 
whereas others are markedly symptomatic with minor aberrations in these test results. Some reports suggest that the measurement of serum soluble interleukin 2 receptors (sIL-2R), derived from surface bound IL-2R in vivo, is a more reliable index of global clinical activity in patients with SLE, specifically reflecting subclinical immune activity with respect to antibodies to dsDNA and complement levels. ${ }^{12}$ This study investigates urine neopterin as a parameter of disease activity in an unselected group of patients with SLE, with particular emphasis on the relation between urine neopterin and certain patterns of organ disease and differing treatment regimens.

\section{Patients and methods \\ PATIENTS}

Sixty eight patients attending the connective tissue disease clinics who fulfilled four or more of the 1982 revised American Rheumatism Association (ARA) criteria for the classification of $\mathrm{SLE}^{13}$ were prospectively studied. A total of 115 matched urine and serum samples were obtained from these patients over a period of 12 months. In addition, 65 apparently healthy controls supplied urine samples for analysis and 19 of the 65 healthy controls volunteered serum samples for estimations of sIL-2R (table 1). None of the patients or controls had a concomitant viral or bacterial infection or disorders other than SLE at the time of investigation. This study was approved by the Nottingham University Hospital ethics committee.

The computerised British Isles Lupus Assessment Group (BILAG) index ${ }^{14}$ was used to score SLE disease activity by a single observer (KLL). The index consists of 86 questions covering eight organ based systems, namely; general mucocutaneous, nervous, musculoskeletal, cardiovascular, vasculitis, renal, and haematological. A score of either ' $\mathrm{A}$ ' or ' $\mathrm{B}$ ' in any of these organ systems was considered to represent active disease.

\section{LABORATORY MEASUREMENTS}

Determination of neopterin in early morning urine samples was by reversed phase high performance liquid chromatography as described previously ${ }^{15}$ with minor modifications. In summary, urine samples, protected from light and stored frozen, were centrifuged to remove debris, diluted one in 10 with water containing dimethylpterine as an internal standard and injected directly onto a

Table 1 Selected clinical and demographic features of the control group and patients with systemic lupus erythematosus (SLE)

\begin{tabular}{llll}
\hline Features & \multicolumn{2}{l}{ Control groups } & \multirow{2}{*}{$\begin{array}{c}\text { Patients with } S L E \\
(n=68)\end{array}$} \\
\cline { 2 - 3 } & $\begin{array}{l}\text { Neopterin } \\
(n=65)\end{array}$ & $\begin{array}{c}s I L-2 R \\
(n=19)^{\star}\end{array}$ & \\
\hline Mean (SD) age (years) $t$ & $45(12 \cdot 6)$ & $42(10 \cdot 6)$ & $\begin{array}{c}43(12 \cdot 8) \\
\text { Male/female }\end{array}$ \\
Mean (SD) disease duration (years) & $2 / 63$ & $0 / 19$ & $\begin{array}{c}3 / 65 \\
\text { Mean number of ARA criteria fulfilled }\end{array}$ \\
\hline
\end{tabular}

* $\mathrm{sIL}-2 \mathrm{R}=$ soluble interleukin 2 receptor; $\mathrm{ARA}=$ American Rheumatism Association tp $>0.05$ by ANOVA.
Techsphere 5 ODS column (HPLC Technology Ltd). A binary gradient elution was used with an initial mobile phase of $2 \%$ methanol in $15 \mathrm{mmol} / \mathrm{l}$ phosphate buffer, $\mathrm{pH}$ 6.4 , increasing to $25 \%$ methanol after 12 minutes, and neopterin was detected by its natural fluorescence $\left(\lambda_{\text {ex }} 353 \mathrm{~nm} ; \lambda_{\text {em }} 438 \mathrm{~nm}\right)$. Creatinine was determined separately using a kinetic alkaline picrate (Jaffe) method and neopterin excretion was expressed as $\mu \mathrm{mol} / \mathrm{mol}$ creatinine.

Serum sIL-2R was measured using a commercially available sandwich enzyme linked immunosorbent assay kit (Cellfree, T Cell Diagnostics, Cambridge, MA, USA). Results were expressed in U/ml relative to a set of standards supplied with the kit.

Other laboratory determinants were performed by standard methods: haemoglobin and white blood cell count with absolute differential count using a Sysmex NE8000 instrument; ESR by the Seditainer ESR system; serum urea and electrolytes on an Ektachem 700XR instrument (Kodak Diagnostic Ltd); plasma C3 and C4 by nephelometry; plasma C3 degradation products $(\mathrm{C} 3 \mathrm{dg}$ ) by a double decker immunodiffusion method; and antibodies to dsDNA using an ELISA kit from Diamedic Corporation.

\section{STATISTICAL PROCEDURE}

Appropriate use of Student's $t$ test and ANOVA enabled comparisons of age, disease duration, and number of ARA criteria fulfilled between groups. For non-parametric study variables, Spearman rank correlation coefficients were computed for pairs of continuous data and the Mann Whitney $U$ test was used to compare continuous variables between two subgroups. When there were more than two subgroups the Kruskall Wallis $H$ test was used. To avoid statistical bias, only data from the initial assessment of patients who had more than one assessment during the study period were included in the correlation analysis.

Forward stepwise logistic regression analysis was chosen to identify the best predictor of SLE disease activity. The predictive variables (represented in binary format) were ESR, C3, $\mathrm{C} 4, \mathrm{C} 3 \mathrm{dg}$, antibodies to dsDNA dichotomised at 100 and $300 \mathrm{IU} / \mathrm{ml}$, serum sIL-2R dichotomised at $700,750,800$, and $850 \mathrm{U} / \mathrm{ml}$, and urine neopterin dichotomised at 200, 250, 300 , and $350 \mu \mathrm{mol} / \mathrm{mol}$ creatinine. Abnormal results were defined as ESR $>10 \mathrm{~mm} /$ hour, $\mathrm{C} 3<0.63 \mathrm{~g} / \mathrm{l}, \mathrm{C} 4<0.11 \mathrm{~g} / 1$, and $\mathrm{C} 3 \mathrm{dg}>12 \mathrm{U} / \mathrm{ml}$, whereas antibodies to dsDNA cut off values were chosen according to manufacturer's guidelines. Laboratory normal ranges were not available for serum sIL-2R and urine neopterin. Consequently four different levels were used for each parameter to determine the best predictive level for active disease. For this analysis, the programs EGRET (epidemiological graphics, estimations and testing package analysis module (PECAN) version 0.26.6; EPIXACT version $0.03^{\circ} 1985-91$, 

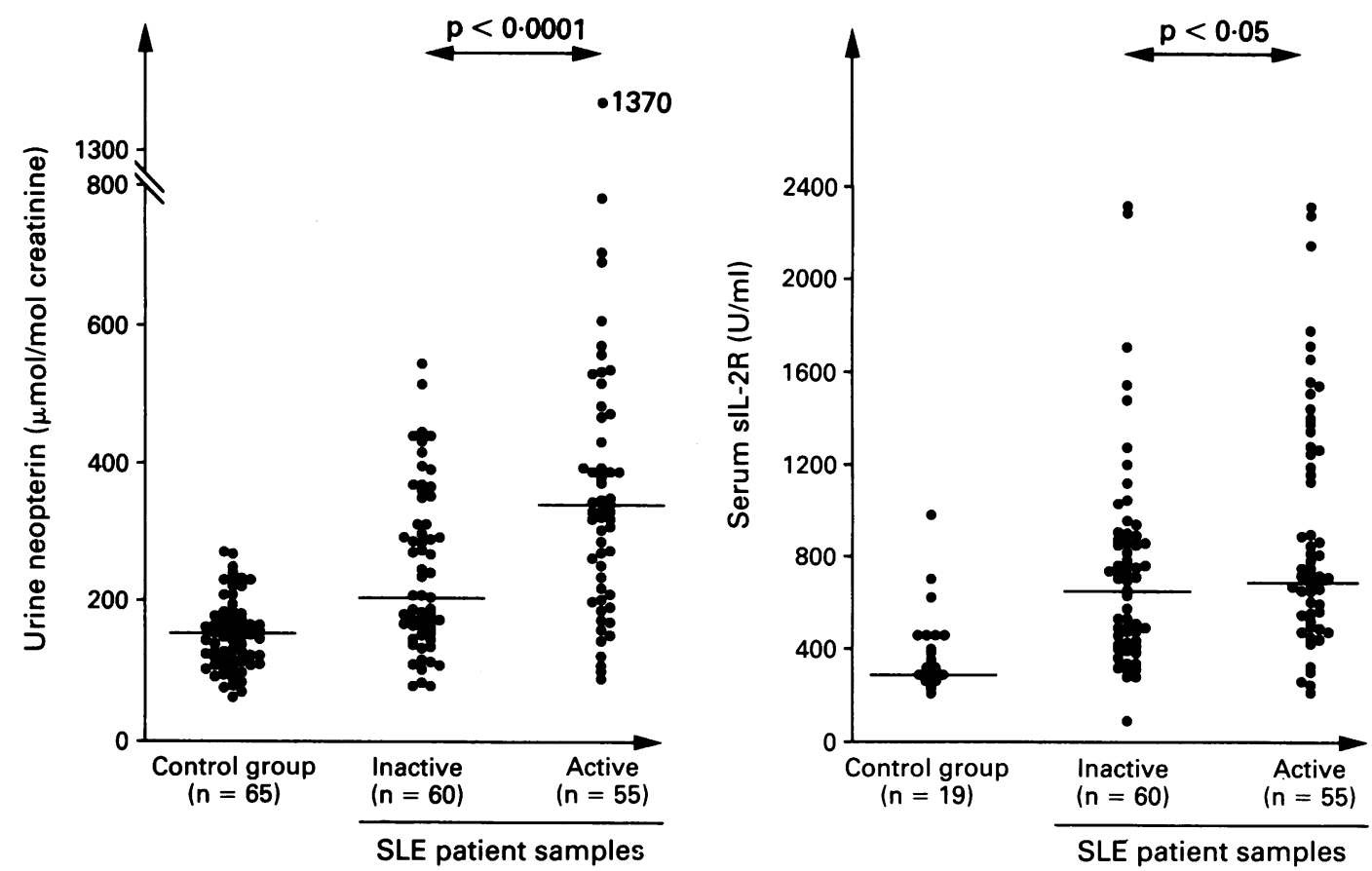

Figure 1 Urine neopterin and serum soluble interleukin 2 receptor $(s I L-2 R)$ values in patients with active and inactive systemic lupus erythematosus (SLE) and their corresponding control groups. The median values of each group is represented by the solid line.

SERC and CYTEL) were used; $\mathrm{p}<0.05$ was considered significant.

The sensitivity, specificity, and positive and negative predictive values for urine neopterin as a diagnostic test were calculated using standard formulae. ${ }^{16}$

\section{Results}

Using the BILAG criteria, $55(48 \%)$ of the matched urine and serum samples were classified as being from patients with SLE with active disease and $60(52 \%)$ from patients with inactive disease. Both patient groups were found, using the Student's $t$ test, to be comparable for age, disease duration and number of ARA criteria fulfilled (data not shown). Of the 55 active samples, 19 (35\%) were from patients with activity in more than one organ system and $36(65 \%)$ were from patients with activity in only one organ system (one general system, eight mucocutaneous system, five nervous system, four musculoskeletal system, four vasculitis, two renal system, and 12 haematological system).

A total of $107(93 \%)$ of the samples were from patients receiving drugs at the time of assessment with 21 patients receiving cytotoxic drugs, 27 patients receiving prednisolone, 48 patients receiving a combination of prednisolone and cytotoxic drugs, and 11 patients receiving hydroxychloroquine.

Figure 1 shows the disease activity, urine neopterin, and serum sIL-2R values in the 115 SLE samples and values in their respective control groups. The median urine neopterin value was significantly higher $(p<0.0001)$ for the whole SLE group $(286 \mu \mathrm{mol} / \mathrm{mol}$ creatinine, range 78-1370) than for the control group $(149 \mu \mathrm{mol} / \mathrm{mol}$ creatinine, range 62-273). In the SLE group the median urine neopterin value was increased more than twofold in samples taken from patients with active disease $(333 \mu \mathrm{mol} / \mathrm{mol}$ creatinine, range 91-1370) but only 1.4 times for samples from patients with inactive disease $(209 \mu \mathrm{mol} / \mathrm{mol}$ creatinine, range 78-544) compared with that of the control group. Nevertheless, the active and inactive groups were shown to have significantly higher urine neopterin values than controls $(p<0.0001)$ and the urine neopterin values for the active group were significantly higher than the inactive group $(p<0.0001)$

The SLE group was found to have a significantly higher median serum sIL-2R (723 $\mathrm{U} / \mathrm{ml}$, range 110-2332) than the control group (340 U/ml, range 220-980) with $\mathrm{p}<0.0001$. Serum sIL-2R levels for the active and inactive SLE groups, with medians of $740 \mathrm{U} / \mathrm{ml}$ (range 207-2309) and $720 \mathrm{U} / \mathrm{ml}$ (range 110-2332) respectively, were significantly higher than controls $(p<0.0001)$ but the difference in serum sIL-2R levels between the active and inactive SLE groups only reached $\mathrm{p}<0.05$.

Figure 2 shows the distribution for ESR, antibodies to dsDNA and plasma C3, C4, and $\mathrm{C} 3 \mathrm{dg}$ in the active and inactive SLE groups. Plasma C3 and C4 were significantly lower and ESR and plasma C3dg were significantly higher in the active group. Antibodies to dsDNA were significantly raised in the active group even though 32 of the inactive and 10 of the active samples had values $<100 \mathrm{IU} / \mathrm{ml}$, defined in the test as a negative result.

A highly significant correlation was found between urine neopterin and serum sIL-2R with $\mathrm{r}=0.51, \mathrm{p}<0.0001$ (fig 3). Correlations were also found with $\operatorname{ESR}(r=0 \cdot 46, p=0.0001)$, C3 $(\mathrm{r}=-0.29, \quad \mathrm{p}=0.016), \quad \mathrm{C} 4 \quad(\mathrm{r}=-0.32$, $\mathrm{p}=0.0076)$ and $\mathrm{C} 3 \mathrm{dg}(\mathrm{r}=0.34, \mathrm{p}=0.0045)$. No significant correlation with antibodies to dsDNA was detected.

Only two study parameters, urine neopterin $>300 \mu \mathrm{mol} / \mathrm{mol}$ creatinine and plasma $\mathrm{C} 4$ 

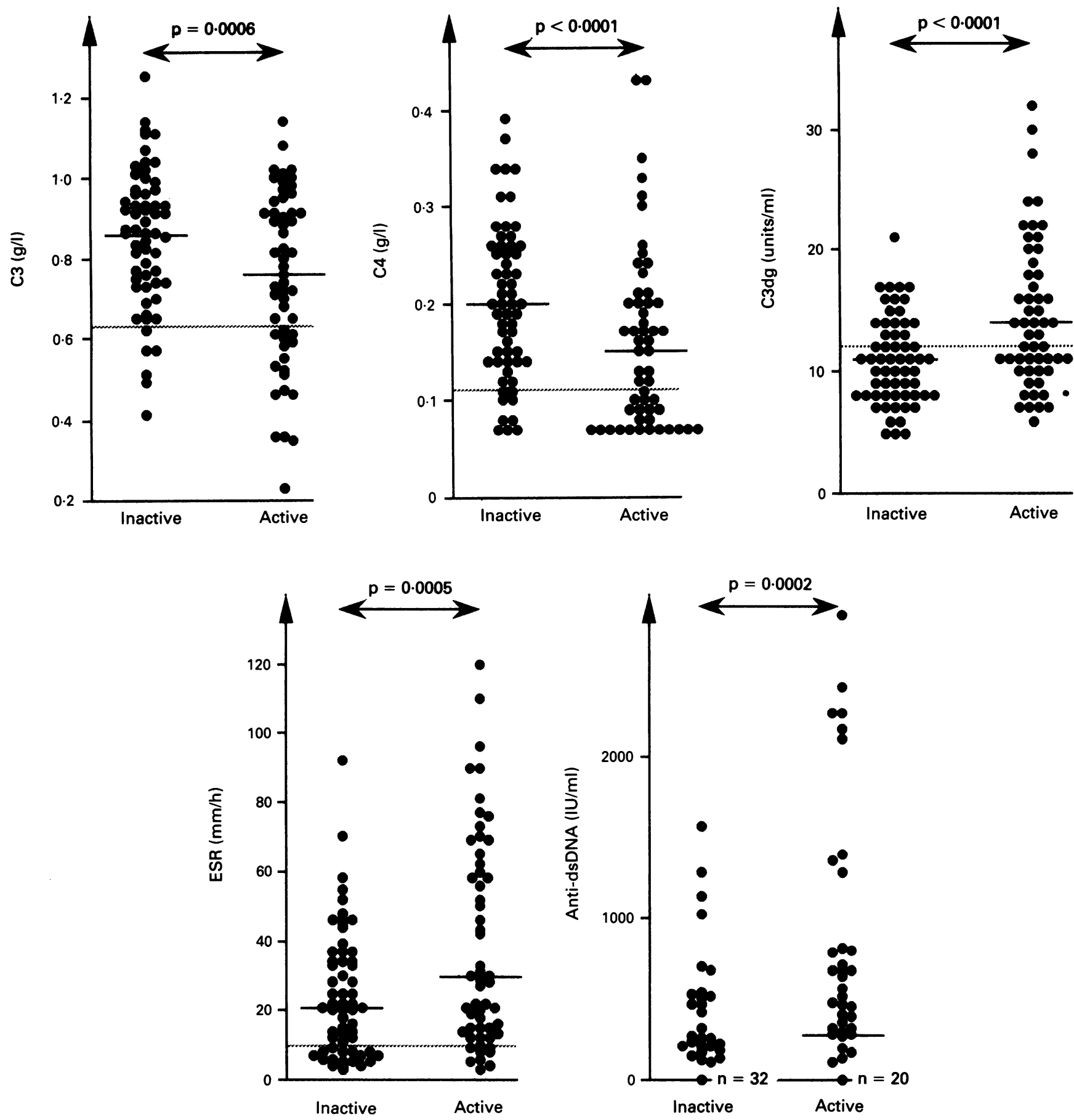

Figure 2 Distribution of plasma C3, C4 and C3dg, erythrocyte sedimentation rate (ESR), and antibodies to double stranded (DNA) (anti-dsDNA) in patients with active and inactive systemic lupus erythematosus. Medians shown by solid line; broken line is normal laboratory range.

$<0 \cdot 11 \mathrm{~g} / 1$, were significant predictors of SLE disease activity using multivariate logistic regression analysis. Urine neopterin $>300$ $\mu \mathrm{mol} / \mathrm{mol}$ creatinine was the most significant of the two with an odds ratio of $3.51(95 \%$ confidence interval 1.55 to $7.93, \mathrm{p}=0.003$ ). The odds ratio for plasma $\mathrm{C} 4<0 \cdot 11 \mathrm{~g} / 1$ was $4 \cdot 14(95 \%$ confidence interval 1.53 to $11 \cdot 23$, $\mathrm{p}=0 \cdot 005)$.

Table 2 gives the sensitivity, specificity, and positive and negative predictive values of levels of urine neopterin in identifying disease activity.

When urine neopterin values were compared for active SLE patients receiving different forms of treatment (fig 4), significant differences were found among the four subgroups using the Kruskall-Wallis $H$ test $(p=0.024)$. The subgroup receiving prednisolone and cytotoxic drugs had significantly lower urine neopterin values that the subgroups receiving prednisolone only $(p=0.003)$ and cytotoxic drugs only $(p<0 \cdot 0001)$. A similar analysis for serum sIL2R, ESR, antibodies to dsDNA, and plasma C3, C4, and C3dg showed that the subgroups receiving prednisolone and cytotoxic drugs as well as those receiving cytotoxic drugs only had significantly higher plasma C3 levels than prednisolone subgroup $(p<0 \cdot 0001)$. No significant differences were found for other subgroup comparisons for each of these parameters.

Urine neopterin values for patients with activity in multiple organ systems (median 389, range 108-783) were significantly higher than 


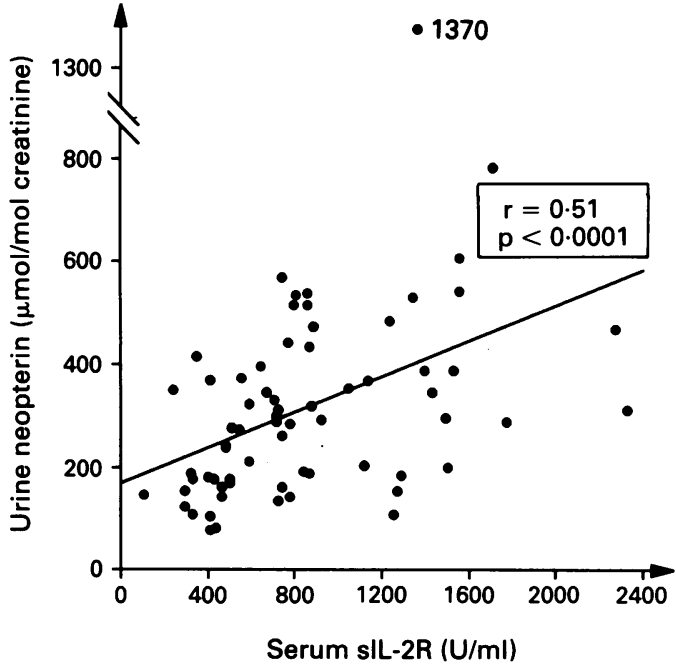

Figure 3 Correlation between serum soluble interleukin 2 receptor (sIL-2R) and urine neopterin in 68 patients with systemic lupus erythematosus.

Table 2 Sensitivity, specificity and positive and negative predictive values of levels of urine neopterin as a determinant of disease activity in patients with systemic lupus erythematosus

\begin{tabular}{|c|c|c|c|c|c|}
\hline \multirow{2}{*}{\multicolumn{2}{|c|}{$\begin{array}{l}\text { Urine neopterin levels } \\
\text { ( } \mu \text { mol/mol creatinine) }\end{array}$}} & \multirow{3}{*}{$\begin{array}{l}\text { Sensitivity } \\
(\%)\end{array}$} & \multirow{3}{*}{$\begin{array}{l}\text { Specificity } \\
(\%)\end{array}$} & \multicolumn{2}{|c|}{ Predictive values (\%) } \\
\hline & & & & Positive & Negative \\
\hline Active disease & Inactive disease & & & & \\
\hline $\begin{array}{l}>350 \\
>300 \\
>250 \\
>200\end{array}$ & $\begin{array}{l}\leqslant 350 \\
\leqslant 300 \\
\leqslant 250 \\
\leqslant 200\end{array}$ & $\begin{array}{l}42 \\
62 \\
71 \\
78\end{array}$ & $\begin{array}{l}77 \\
72 \\
57 \\
47\end{array}$ & $\begin{array}{l}62 \\
67 \\
60 \\
57\end{array}$ & $\begin{array}{l}59 \\
67 \\
68 \\
70\end{array}$ \\
\hline
\end{tabular}

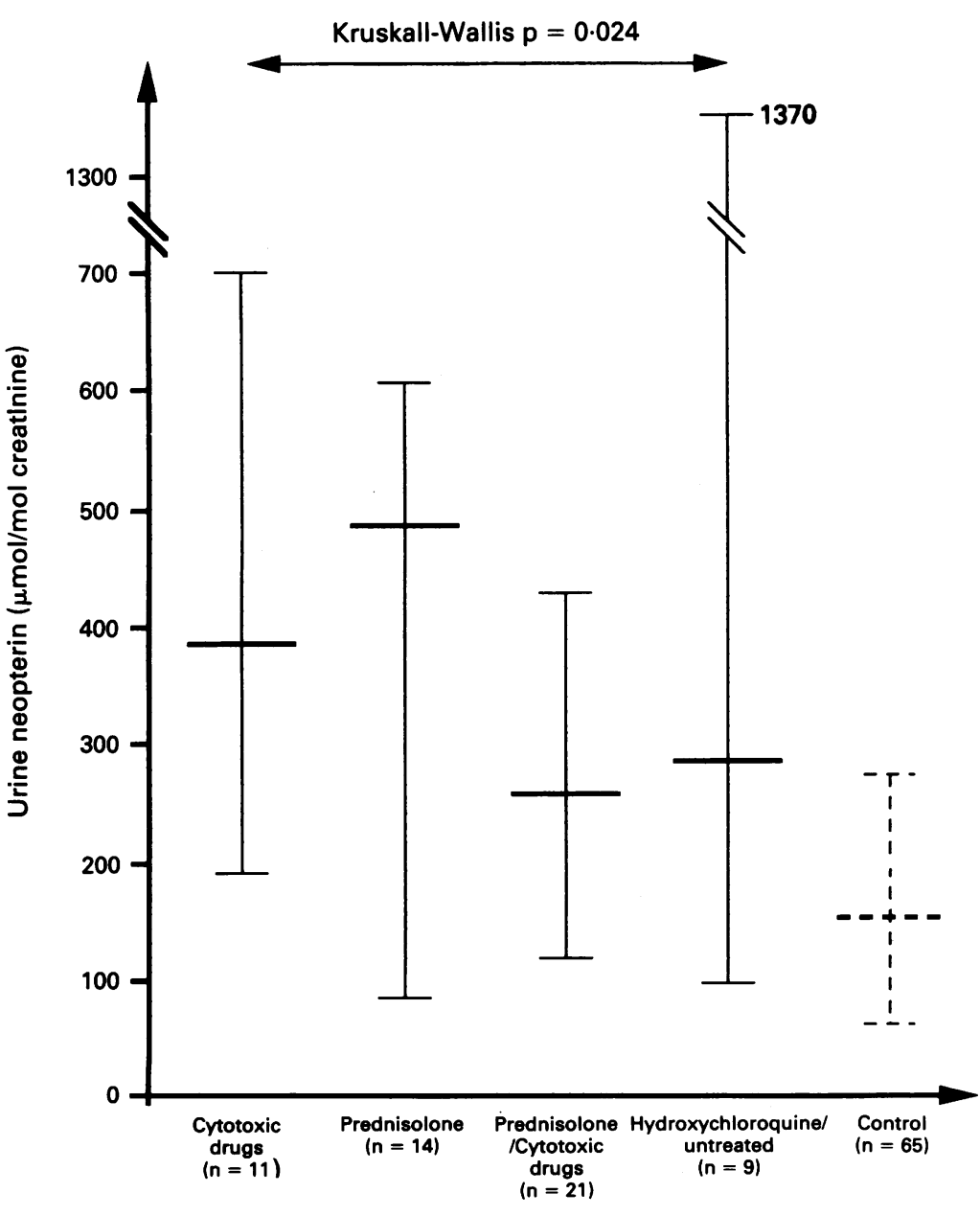

Treatment regimens

Figure 4 Medians (horizontal rule) and ranges of urine neopterin concentrations in subgroups of patients with active systemic lupus erythematosus receiving four different treatment regimens. in patients with activity in a single organ system (median 305, range 91-1370) $(\mathrm{p}=0 \cdot 0002)$, but no significant differences in urine neopterin values were observed between subgroups of patients with activity in a specific organ system (data not shown).

\section{Discussion}

We have shown a highly significant association between urine neopterin and disease activity in a group of patients with diverse clinical manifestations of SLE. Significantly increased urine neopterin values were found in patients with active and inactive SLE compared with healthy controls. Previously only patients with renal lupus have been investigated, ${ }^{17}$ in whom urine neopterin correlated with SLE disease activity according to the Winfield criteria, ${ }^{18}$ but not with the clinical course or severity of renal disease. The raised urine neopterin values in patients, with inactive SLE probably represent continuous low grade activation of the cellular immune system without an association with clinical symptoms or apparent deterioration in the function of a major organ as defined by the BILAG index. Low grade cellular immune activation in inactive SLE is further suggested by our serum sIL-2R data, which showed significantly higher serum sIL-2R levels in patients with SLE than in controls regardless of their disease activity; this agrees with other studies. ${ }^{19-24}$ The continuous cellular immune activation may be prognostically significant.

There was considerable overlap in serum sIL-2R values between the patients with active and inactive SLE. Serum sIL-2R values tend to be higher in active than in inactive disease, however, and the difference in their median values, though small, remained significant at the $\mathrm{p}<0.05$ level. This finding suggests that other factors, in particular renal function, may have an important influence on serum sIL-2R levels. ${ }^{25} 26$ This is in contrast with previous reports of serum sIL-2R as a sensitive marker of disease activity in patients with SLE. ${ }^{19} 2728$

We have also shown that ESR, antibodies to dsDNA and plasma C3, C4, and C3dg are significantly different in patients with active than inactive SLE based on the BILAG index. Plasma C3, C4, and C3dg had a low sensitivity in differentiating between active and inactive disease as in the 55 patients with active SLE; only 17 had low C3, 21 had low C4 and 30 had high C3dg values on our laboratory scales. In contrast, the ESR had poor specificity as $72 \%$ of the group with inactive SLE were found to have raised levels. The proportion of patients with active disease and antibodies to dsDNA detectable by ELISA (64\%) was perhaps lower than expected. Our patient cohort did not have an overrepresentation of patients with lupus nephritis, however, which may have influenced certain previous studies. ${ }^{29} 30$

The highly significant correlation between urine neopterin and serum sIL-2R, ESR, and plasma C3, C4, and C3dg underlines the close association of neopterin with clinical activity in SLE. Urine neopterin $>300 \mu \mathrm{mol} / \mathrm{mol}$ 
creatinine and plasma $\mathrm{C} 4<0 \cdot 11 \mathrm{~g} / \mathrm{l}$ were found to be significant predictors of SLE disease activity on multivariate logistic regression analysis compared with the other study parameters. Urine neopterin at this level was further shown to have the best positive predictive value $(67 \%)$ with a sensitivity and specificity of 62 and $72 \%$ respectively. In contrast, plasma $\mathrm{C} 4<0 \cdot 11 \mathrm{~g} / 1$ showed less discriminatory power due to a greater overlap between the patients with active and inactive SLE. These calculations are based on the assumption that the BILAG index is $100 \%$ sensitive and $100 \%$ specific in defining SLE activity, but there remains no general agreement on the most valuable SLE disease activity index.

Why the subgroup receiving prednisolone and cytotoxic drugs had significantly lower urine neopterin values than those receiving prednisolone or cytotoxic drugs only is not obvious. Treatment with drugs, for example, steroids, affects the proportion of lymphocyte subpopulations and the expression of cell surface molecules and hence could potentially influence neopterin production. ${ }^{2}$ Drugs do affect clinical disease activity and it is difficult to investigate a possible additional direct effect of drugs on neopterin levels. Analyses of the other study parameters suggest that the patients receiving prednisolone only generally had more active disease than the other subgroups, but differences did not reach statistical significance apart from plasma C3 concentrations. Urine neopterin therefore appears to be a reflection of treatment efficacy in suppressing disease activity rather than a direct drug related effect, and this agrees with the findings in other inflammatory diseases. ${ }^{31} 32$ In view of the small numbers in this part of the study, however, a type I error cannot be excluded and further studies are required to clarify this issue.

No significant differences between urine neopterin in patients with different patterns of organ system disease were observed, suggesting that increased urine neopterin excretion and hence the activation of the cellular immune system occurs regardless of the major organ affected in SLE. The significantly higher urine neopterin values in the group with multiple organ system disease agree with these patients having generally more active disease. This is in contrast to changes in levels of antibodies to dsDNA and complement which have been reported to accompany flares in lupus nephritis. ${ }^{30} 33$

Sensitive and accurate radioimmunoassays and high performance liquid chromatographic methods have been developed for the measurement of neopterin in body fluids. ${ }^{15} 34$ We chose to measure neopterin in urine by high performance liquid chromatography as this method has good performance characteristics, is easily automated and is non-invasive. In contrast, serum neopterin levels are dependent on renal function ${ }^{35}$ and the determination of urine neopterin by radioimmunoassay can give erroneous results related to the poor specificity of the antisera. ${ }^{34}$
In conclusion, urine neopterin appears to be the best single parameter of disease activity in patients with SLE. It is a non-invasive, relatively simple and inexpensive test which seems to be clinically useful for assessing and monitoring disease activity and treatment in patients with SLE. It must be noted, however, that it is not specific to SLE nor can it distinguish between disease exacerbations and infective episodes. ${ }^{36}$ Neopterin may prove to be an early indicator of disease flares in patients with SLE but this would require long term serial studies.

We thank Dr M Atta for his help in running the enzyme linked immunosorbent assays for serum interleukin 2 receptor an antibodies to double stranded DNA, Mr J Hughes for urine neopterin measurements, and Miss S Smith for statistical advice.

1 Via C, Handwerger B. T-cell and B-cell function in lupus. Curr Opin Rheumatol 1992; 4: 630-4.

2 Raziuddin $S$, Nur $M$, Al-Waber A. Increased circulating HLA-DR+CD4+T cells in systemic lupus erythematosus: alterations associated with prednisolone therapy. Scand $\mathscr{f}$ Immunol 1990; 31: 139-45.

3 Hishikawa T, Tokano Y, Sekigawa I, et al. HLA-DP+T cell and deficient interleukin-2 production in patients with systemic lupus erythematosus. Clin Immunol Immunopathol 1990; 55: 285-96.

4 Tabata H, Hara M, Kitani A, et al. Expression of TLiSAl on $T$ cells from patients with rheumatoid arthritis and systemic lupus erythematosus. Clin Immunol Immunopathol 1989; 52: 366-75.

5 Wigfall D, Sakai R, Wallace D, Jordan S. Interleukin-2 receptor expression in peripheral blood lymphocytes from systemic lupus erythematosus patients: relationship to clinical activity. Clin Immunol Immunopathol 1988; 47 354-62.

6 Wachter H, Fuchs D, Hausen A, Reibnegger G, Werner E Neopterin as marker for activation of cellular immunity: immunologic basis and clinical application. Adv Clin Chem 1989; 27: 81-141.

7 Heintel D, Ghisla H, Curtius H, Niederwieser A. Biosynthesis of tetrahydrobiopterin: possible involvement of tetrahydrobiopterin intermediates. Neurochem Int 1984; 6: $141-55$.

8 Huber C, Fuchs D, Hausen A, et al. Pteridines as a new marker to detect human $T$ cells activated by allogeneic or modified self major histocompatibility complex (MHC) determinants. F Immunol 1983; 130: 1047-50

9 Huber C, Batchelor J, Fuchs D, et al. Immune responseassociated production of neopterin. Release from macrophages primarily under control of interferongamma. F Exp Med 1984; 160: 310-6.

10 Andert S, Griesmacher A, Zuckerman A, Muller M Neopterin release from human endothelial cells is triggered by interferon-gamma. Clin Exp Immunol 1992; 88: $555-8$.

11 Rabinoff $M$. Possible uses of urinary neopterin and biopterin measurement. Med Hypotheses 1989; 29: $241-3$.

12 Rubin L. The soluble interleukin-2 receptor in rheumatic disease. Arthritis Rheum 1990; 33: 1145-8.

13 Tan E, Cohen A, Fries J, et al. The 1982 revised criteria for the classification of systemic lupus erythematosus. the classification of systemic

14 Symmons D, Coppock J, Bacon P, et al. Development and assessment of a computerised index of clinical disease activity in systemic lupus erythematosus. $Q \mathcal{F}$ Med 1988 258: $927-37$

15 Slazyk W, Splerto F. Liquid-chromatographic measuremen of biopterin and neopterin in serum and urine. Clin Chem 1990; 36: 1364-8.

16 Altman D. Practical statistics for medical research. 1st ed. London: Chapman and Hall, 1991: 414-6.

17 Leohirun L, Thuvasethakul P, Sumethkul V, Pholcharoen $\mathrm{T}$, Boonpucknavig V. Urinary neopterin in patients with systemic lupus erythematosus. Clin Chem 1991; 37: system

18 Winfield J, Brunner C, Davis J, William M. Assessment of disease activity in SLE [abstract]. Arthritis Rheum 1972 15: 462 .

19 Airo P, Braga S, Prati E, et al. Evaluation of serum levels of soluble interleukin-2 receptor as an indicator of disease of soluble interleukin-2 receptor as an indicator of disease 1992; 11: $97-100$

20 Wolf $R$, Brelsford $W$. Soluble interleukin-2 receptors in systemic lupus erythematosus. Arthritis Rheum 1988; 31 systemic

21 Campen D, Horwitz D, Quismorio F, Ehresmann G, Martin W. Serum levels of interleukin-2 receptor and activity of rheumatic diseases characterised by immune system activation. Arthritis Rheum 1988; 31: 1358-64. 
22 Huang Y, Perrin L, Miescher P, Zubler R. Correlation of $T$ and $B$ cell activities in vitro and serum IL-2 levels in systemic lupus erythematosus. $\mathcal{F}$ Immunol 1988; 141 827-33.

23 Semenzato G, Bambara L, Biasi D, et al. Increased serum levels of soluble interleukin-2 receptor in patients with systemic lupus erythematosus

24 Manoussakis M, Papadopoulos G, Drosos A Manoussakis M, Papadopoulos G,
Moutsopoulos $H$. Soluble interleukin 2 receptor Moutsopoulos $\mathrm{H}$. Soluble interleukin 2 receptor molecules in the serum of patients with autoimmun

25 Nelson D, Wagner D, Marcon L, et al. An analysis of soluble IL-2 receptors in human neoplastic disorders. In: Albertini A, Lentant C, Poeletti R, ed. Biotechnology in clinical medicine. New York: Raven Press, 1987.

26 Manoussakis M, Germanidis G, Drosos A, Moutsopoulos H. Impaired urinary excretion of soluble IL-2 receptor in patients with systemic lupus erythematosus and rheumatoid arthritis. Lupus 1992; 1: 105-9.

27 ter Borg E, Horst G, Limburg P, Kallenberg C. Changes in plasma levels of interleukin-2 receptor in relation to disease exacerbations and levels of anti-dsDNA and complement in systemic lupus erythematosus. Clin Exp Immunol 1990; 82: 21-6.

28 Ward M, Dooley M, Christenson V, Pisetsky D. The relationship between soluble interleukin 2 receptor levels and antidouble stranded DNA antibody levels in patients and antidouble stranded DNA antibody levels in patients
with systemic lupus erythematosus. $\mathcal{F}$ Rheumatol 1991; 18: with system 40 .
29 ter Borg E, Horst G, Hummel E, Limburg P, Kallenberg C. Rises in anti-double stranded DNA antibody levels prior to exacerbations of systemic lupus erythematosus are not merely due to polyclonal B cell activation. Clin Immunol Immunopathol 1991; 59: 117-28.

30 ter Borg E, Horst G, Hummer E, Limburg P, Kallenberg C. Measurement of increases in anti-double-stranded DNA antibody levels as a predictor of disease exacerbations in systemic lupus erythematosus: a long-term, bations in systemic lupus erythematosus: a long-term
prospective study. Arthritis Rheum 1990; 33: 634-43.

31 Niederwieser D, Fuchs D, Hausen A, et al. Neopterin as a new biochemical marker in the clinical assessment of ulcerative colitis. Immunobiology 1985; 170: 320-6.

32 Prior C, Bollbach R, Fuchs D, et al. Urinary neopterin, a marker of clinical activity in patients with Crohn's disease. Clin Chim Acta 1986; 155: 11-21.

33 Swaak A, Aarden L. Statius van Eps L, Feltkamp T. AntidsDNA and complement profiles as prognostic guides in systemic lupus erythematosus. Arthritis Rheum 1979; 22

34 Rokos H, Rokos K. A radioimmunoassay for determination of D-erythro-neopterin. In: Blair J A, ed Chemistry and biology of pteridines. Berlin and New York: de Gruyter, 1983: 815-9.

35 Werner E, Bichler A, Daxenbichler G, et al. Determination of neopterin in serum and urine. Clin Chem 1987; 33: 62-6.

36 Niederwieser A, Joller P, Seger R, et al. Neopterin in AIDS other immunodeficiencies, and bacterial and vira infections. Klin Wochenschr 1986; 64: 333-7. 